\title{
It is ethical to diagnose a public figure one has not personally examined
}

\author{
John Gartner, Alex Langford and Aileen O'Brien
}

\section{Summary}

Should psychiatrists be able to speculate in the press or social media about their theories? John Gartner argues the risk to warn the public of concerns about public figures overrides the duty of confidentiality; whereas Alex Langford suggests this is beyond the ethical remit of psychiatric practice.

\section{Declaration of interest}

A.O'B is joint debates and analysis Editor of the British Journal of Psychiatry. J.G. is the founder of Duty To Warn, an association of mental health professionals who advocate the president's removal under the 25th Amendment on the grounds that he is psychologically unfit and dangerous.

\section{Keywords}

Diagnosis; history of psychiatry; media.

\section{Copyright and usage}

(c) The Royal College of Psychiatrists 2018.

\section{Introduction}

'I think a guy running for office who says exactly what he really thinks would astound a hell of a lot of people around the country' (p. 68). ${ }^{1}$ The words of an anti-establishment maverick businessman turned politician, standing as the Republican candidate for the US Presidency. Public disquiet about his mental health leads to psychiatrists speculating about potential psychiatric diagnoses.

This is 1964, the candidate is Barry Goldwater and the case leads to the American Psychiatric Association (APA) stating that it is unethical for a psychiatrist to offer a professional opinion unless he or she has conducted an examination and has been granted proper authorization for such a statement'. ${ }^{2}$ During his tenure as President of the Royal College of Psychiatrists Simon Wessely suggested UK psychiatrists should abide by the same principle.

However, on both sides of the Atlantic speculation about the mental health of public figures is rife. When this debate was commissioned the aim was to avoid a focus on Donald Trump, but it became apparent that this would be disingenuous; it is the debate about Trump which is taxing the limits of Goldwater, and Trump is the reason this issue is being discussed.

Here, US and UK psychiatrists - John Gartner and Alex Langford - debate the ethical principles and practical implications of abiding with the Goldwater rule or UK equivalent. Should speculation about diagnosis be limited to the individual's doctor with their consent; or is there a duty to warn the public if we are concerned about the mental health of our leaders?

Aileen O'Brien

\section{For}

In 1964, a now defunct magazine, Fact, published a survey of psychiatrists weighing in on the mental health of then presidential candidate Barry Goldwater: '1,189 psychiatrists say Goldwater is psychologically unfit to be president!' ${ }^{3}$ Goldwater lost the election, in part because his opponent, Johnson, exploited the image of Goldwater as an unstable finger on the nuclear button. But after the election Goldwater won his libel suit against the magazine. Embarrassed by the incident, the APA adopted the principle that a psychiatrist should not diagnose a public figure unless they had both personally examined them and received their permission.
Few in the general public had ever heard of this obscure rule until the emergence of Donald Trump. Many mental health professionals felt they had a 'duty to warn' the public about what they viewed as the frank signs of dangerous mental disturbance they saw in Trump, just as they have an ethical and legal statutory 'duty to warn' any potential victims of violence who might be threatened by one of their patients. This ran afoul of the Goldwater rule, precipitating enormous controversy and debate, not only within the profession, but in the US media, as well as that of other countries, including the UK.

'Duty To Warn', an association of mental health professionals that I lead, advocates for Trump's removal on the grounds that in their view he is dangerously psychologically disordered and unfit, arguing that warning the public about a dangerous president trumps the Goldwater rule.

\section{Goldwater was intended to be a 'principle' not a 'rule'}

When I spoke with Dr Allen Dyer, the last living member of the original APA ethics committee that drafted Goldwater in 1974, he said the current interpretation of Goldwater had drifted far from the framers' intentions. Goldwater was meant to be a 'principle,' that professionals needed to keep in mind, not a 'rule' to be followed slavishly in all circumstances. The 'Goldwater Principle' has been 'ossified,' applying 'rule-based legalistic thinking to a matter of professional judgment'.

In ethics there is often a conflict between two competing principles. 'There might be a conflict within the conscience of a particular psychiatrist between the principle of restraint and a more overriding principle, like the duty to warn' he said. The resolution of that conflict should be 'up to the professional judgment of the individual professional'. Therefore, Goldwater should not 'constrain psychiatrists from making a useful contribution to society' if that means warning about a 'potentially dangerous president'. The Goldwater principle was not intended as 'a gag order'.

This May, the APA expanded Goldwater, barring not just diagnosis, but the 'rendering any professional opinion' whatsoever about a public figure. Dr Rebecca Brendel, of Harvard, a consultant to the APA ethics committee, wrote: 'even if a "psychiatrist, in good faith, believes a public individual poses a threat to the country or national security,' he should remain silent". ${ }^{4}$

\section{More important than national security?}

Imagine a gunman entering the New York Public library, brandishing a pistol. If a patron shouted 'call the police,' librarian Brendel 
would chastise them: 'Sir, you must remain silent. No speaking allowed in the library'. Yes, that is a rule - but no sane person would follow it under those circumstances.

Unfortunately, this analogy understates our actual situation. Trump is brandishing, not just a gun, but nuclear weapons, and he has threatened to 'destroy the country of North Korea'. See something, say nothing, would appear to be the current national security policy of the APA.

\section{An accurate diagnosis does not necessarily require a psychiatric interview}

The critical comments about Goldwater in Fact, took place in 'the era of DSM-II, which was theoretically based, relying largely on psychoanalytic theory,' wrote Dyer. ${ }^{5}$ Charges such as he was 'scarred by his potty training' or a 'latent homosexual' were 'frivolous extrapolations that had no basis in reality'. 'We might have written the principle differently if DSM III had existed at that time,' said Dyer. 'We might not have made such a hard and fast stand on interviewing the patient,' as a necessary condition for making a public statement. Because 'then it would be possible to explain to the public our evidence and rationale'.

The goal of DSM-III was to establish diagnostic criteria that were behaviourally observable and did not rely either on a clinician's theoretical outlook or inferences about internal psychic processes. From that, it logically follows that if I could directly observe a patient's behaviour, read his communications and hear from close informants, I would be able to make a valid diagnosis. In the case of Donald Trump, I have observed literally hundreds of hours of Donald Trump's behaviour. I have read thousands of his tweets. And I have read the testimony of dozens of informants. I would dare say I have a stronger basis for diagnosing Trump than most of the patients in my practice.

'The Goldwater Rule privileges the personal interview as the standard by which a practitioner may form professional opinions,' wrote Kroll \& Pouncey, ${ }^{6}$ even though research shows the psychiatric interview is not the magic Rosetta Stone to divining a patient's illness. 'Personal examinations are notoriously flawed ... because of conscious (intentional) and unconscious distortions' ${ }^{6}$ In particular, patients with severe personality disorders, which I would suggest Trump exhibits, are famously adept at fooling and manipulating others, including therapists. History, records, informants and if possible direct observation, can be far more reliable.

Bandy Lee wrote: 'possibly the oddest experience in my career as a psychiatrist has been to find that the only people not allowed to speak on an issue are those who know the most about it. Hence, truth is suppressed'. ${ }^{7}$ If the only people not allowed to comment on climate change were climate scientists, society would always be kept in the dark. Blindly following Goldwater legalistically paints us into a logical corner - a reductio ad absurdum. Since it appears unlikely that Trump will ever voluntarily consent to a psychiatric interview, the truth about his psychiatric state becomes an unknowable mystery, or simply a matter of opinion, like the existence of God. No matter how grossly impaired Trump may be, or becomes, no matter how overwhelming the evidence, reality will always be unknowable, even if the emperor clearly has no sanity.

We now live in a pre-fascistic society, where the press, science and facts in general are dismissed as fake news. Unfortunately, the Goldwater Rule has given Trump's defenders ammunition to cry: "fake news" in the face of mental health professionals' dire warnings. Since none of us have interviewed Trump, they argue we can't possibly know if he is mentally ill or dangerous, and thus our warnings should be dismissed as false alarms, fomented by unethical, unprofessional, partisan liars. Even our own professional association argues we should be sanctioned, they say. And some have decided to take the sanctioning into their own hands. Many of us have receives multiple death threats. We are trolled by hundreds. My private practice dwindled by half until I realized my Google rating had been downgraded to two stars in response to an organized online effort, involving dozens of people, to systematically drive down my professional rating.

\section{Diagnosis can be essential information for the public's safety}

One of the common arguments against diagnosing Trump is that it is unnecessary. The public can observe his behaviour for themselves, the argument goes and throwing in a diagnosis does not add anything useful to the public debate. On the face of it, it is really hard to believe that our decades, centuries really, of research and clinical experience have no information value.

But more specifically, we know in both psychiatry and medicine, diagnosis yields information about prognosis. Before the election, I wrote in the Huffington Post that Trump was in my view a malignant narcissist. ${ }^{8}$ At that point, in June of 2016, there was still a strong hope that Trump would 'pivot' and become more 'presidential'. I argued, 'the idea that Trump is going to settle down and become presidential when he achieves power is wishful thinking. Success emboldens malignant narcissists to become even more grandiose, reckless and aggressive. Sure enough, after winning the nomination, there has been no "pivot" towards more reasonable behavior and ideas, just the opposite. He has become more shrill, combative and openly racist'. ${ }^{8}$ And, in my view, since winning the election he has, predictably, deteriorated further.

Imagine a different 2016, one where the public had been adequately informed that, contrary to their optimistic hopes, based on a diagnosis, it was far more likely he would become much worse. If the public had been allowed to receive such information, history might have turned out very differently.

\section{You do not have to diagnose to warn}

Many psychiatrists have endeavoured to resolve the Goldwater dilemma by refusing to diagnose him, often explicitly stating, 'I haven't personally examined him so I can't render a diagnosis, but ....'

In some cases, they have educated the public about the diagnostic criteria for various disorders, such as narcissistic personality disorder, for example and let readers draw their own conclusions.

Others have put aside diagnosis altogether, to focus on the many behaviours that they have identified as clear warning signs of dangerousness: lying, impulsivity, a pervasive pattern of exploiting and violating the rights of others, a history of violating norms, lack of remorse, paranoid thinking and incitement to violence.

In the end, this is really the bottom line. The duty to warn does not require a multiaxial diagnosis, but it does require you to warn individuals who are at risk. If someone is bringing a gun to your house, you need only know someone is bringing a gun to your house, regardless of their diagnosis. It is my view, therefore, that what the public needs to know about Donald Trump is that he is dangerous.

But when the APA broadened Goldwater to forbid rendering any 'professional opinion' whatsoever about a public figure they made it impossible for a psychiatrist to resolve this ethical dilemma in any way but silence.

Thus, if you consider silence in the face of rising fascism to be unethical, then the only way to adhere to APA ethics is to behave unethically.

\section{The interest of the public has been sacrificed to protect the psychiatric guild}

'There may be interests in society that are at odds with the interests of the profession'. Dyer said in an article about Goldwater in the 
Washington Diplomat (2017). ${ }^{9}$ The author summarises Dyer's position as: 'The rule was crafted in part to protect the guild'. Embarrassed by the Goldwater incident, the APA feared reckless public statements could diminish the credibility of the profession. But even the most responsible and well-documented statements about public figures are bound to antagonise someone, so speaking out is a no-win for the guild under any circumstances.

Psychiatrist John Zinner told The New Yorker (2017) that the Goldwater rule is 'utterly disingenuous'. ${ }^{10}$ Zinner reported that at a meeting of the Washington Psychiatric Society in March 2017, a 'high official' of the APA, 'defended keeping the Goldwater Rule in place, on the theory that if psychiatrists spoke out against Trump, the government would retaliate by reducing reimbursements to doctors for psychiatric treatment. "It was really not out of ethical concern," Zinner said, but, rather, "concern for our pocketbooks".'

This simple 'pocket book' explanation - and in science the simplest explanation is usually the right one - makes far more sense than the contorted logic offered by Goldwater defenders. But if and to the extent that the profession is choosing its own interests over those of the public, then the Goldwater rule may be considered an example of APA corruption, not ethics.

The German Psychiatric Association said nothing during the rise of Hitler. Should they be our moral role models? As a Jew, I was raised with the mantra 'Never again', which means it is a grave and terrible sin to be silent in the face of rising fascism. Professional silence in the face of evil and madness has real-world consequences. There is a clinical truism: We often bring about the very thing we fear. In an effort to avoid 'embarrassing the profession' the APA has stained it with eternal shame.

John Gartner

\section{Against}

I thank Professor Gartner for his views, but I feel he fundamentally misjudges the role of psychiatry in the modern world. The Goldwater rule, and the many variations of it that are observed by psychiatric organisations around the world, do not shame our profession. Desisting from speculation about diagnoses of public figures is an important and powerful demonstration of ethically informed practice. It also goes some way to addressing some of the more shameful historical practices of psychiatry, and brings us closer to a less stigmatising, more educated and ultimately hopeful future.

To begin with an obvious point, all medical professionals have a central duty to maintain confidentiality. This protects the private information of individual patients, but also our own reputation. Doctors are routinely found to be highly trustworthy in the eyes of an increasingly cynical public. If we loosen our ethical restrictions on the public discussion of medical information, we not only risk scaring away the patients we already have, but also risk the possibility of potential future patients feeling less inclined to see us. In psychiatry more than any other speciality, we should acknowledge the shame and fear that accompanies illness; trustworthiness is an essential prerequisite for an open, therapeutic relationship.

Professor Gartner offers an analogy to support public discussion of diagnosis; namely that of climate change experts not being allowed to talk about climate change. But it does not hold up. Psychiatrists frequently discuss mental illnesses, in a general sense, in print and broadcast media and should be congratulated for doing so. This educates the public about what mental illness is, breaks down stigma and encourages people to get help. It promotes the use of sensible, careful diagnosis in an appropriate setting.

But discussing the mental health of an individual, not least of someone that you have not met, is a different proposition entirely.
This seemingly condones, if not endorses, wild speculation on diagnoses by unqualified people, which has implications. Guesses on social media about possible diagnoses of Trump have included everything from obsessive-compulsive disorder ${ }^{11}$ to delusional disorder, with seemingly no realisation that these entities are not just likely to be wildly incorrect, but may have a shaming, belittling effect on people who really do have these conditions. The public will assume that we take a similarly rash and assumptive approach to diagnosing patients in clinic.

The casual use of mental health terminology can quickly become pejorative, as the British tabloid press have demonstrated. The classic 'Bonkers Bruno' ${ }^{\text {'2 }}$ and the more recent " 1200 killed by mental patients ${ }^{13}$ headlines will only be more likely to be repeated if we openly condone discussion of the mental health of people we have never even met.

Professor Gartner writes as if he has forgotten that the Goldwater rule was established because idle, public conjecturing about a man's mental health may have cost him the presidency. The rule has cut down on such talk, but the stigma, which results from it, has been less easy to eradicate. Thomas Eagleton withdrew as a vice presidential candidate in 1972 as he happened to have an undisclosed history of depression. ${ }^{14}$ British members of parliament have only recently felt that the time is right to disclose their own histories of mental illness. ${ }^{15}$

Certainly, psychiatrists, like all doctors, have a duty to break confidentiality when an imminent or severe risk is posed. This is not hard to justify, and the UK General Medical Council very clearly allows for such actions. However, such allowances were only ever envisaged as applying to the doctor-patient dyad, not the doctor-public figure dyad. ${ }^{16}$ Openly commenting on the potential mental disorder of a public figure because of perceived risk is far less defensible.

Professor Gartner likens this to not being able to shout for help when a gunman enters a library. But this analogy does not hold, because guns and mental disorders are different things. The former is a potential method of carrying out harm, and the latter is a complex, dynamic psychological state that might or might not increase the likelihood of the method being applied. Guns kill people, but mental disorders, without a method through which to act, do not. The situations where the General Medical Council does deem it justifiable to breach confidentiality are usually around the disclosure of a method of harm (i.e. driving when medically unfit, or a stabbing or gunshot wound) rather than particular disorders. To hijack the analogy, if a man holding a gun enters a library, of course it is alright to shout for help. But if a man with a mental illness enters a library, you do not need to shout for help unless they are holding a gun, in which case you would shout about the gun. It is hard to see how disclosing the full psychiatric history of the gunman to the public would add much to their decision-making process.

Often, the psychopathology of the person in question is quite clear to the public anyway, and despite our airs of expertise, a psychiatric label adds nothing meaningful to their appraisal of risk. We can illustrate this with Trump. The whole world is aware of the risks he poses, as well as the cause of those risks; namely his frankly repulsive personality. I cannot comprehend how rolling up all his behaviours and traits into a label, narcissistic personality disorder, and giving it back to the public with an 'expert' warning, should constitute a better judge of the risks he poses than the judgement that has already taken place. Because - and this is important - the American people had a lengthy and excruciating exposure to his words and deeds during the presidential campaigning period. And then they voted for him.

Professor Gartner rightly fears fascism. Yet there are few more characteristically totalitarian acts than removing people from the 
sphere of political influence based on a psychiatric opinion that constitutes nothing more than those people's unpopular views recast as mental illness. Examples of the political abuses of psychiatry are countless. The Soviet Union and China both incarcerated dissidents as 'sluggish schizophrenics' in their dozens, ${ }^{17}$ and Black Americans were hospitalised in the 1960s for espousing civil rights ideas. $^{18}$

However laudable Professor Gartner's aims, it cannot be ignored that issues of public diagnosis only arise when we are confronted by a political landscape that we do not agree with. John McCain, a far more respected politician than Trump, has recently been diagnosed with a brain tumour yet continues to hold his position without challenge, presumably because the medical establishment agrees with his more liberal views.

Neurologists would never dream of publicly discussing McCain's brain tumour with respect to his ability to do his job, just like chest physicians would have been met with disdain for suggesting that Hillary Clinton's campaign bout of pneumonia made her unfit for office. No other speciality would do this, because they recognise the difference between signs of ill health and political behaviour that they do not agree with. Only in psychiatry do we ever feel the need to conflate immorality with illness, and it has done us no good at all.

A diagnosis is not primarily meant to gauge risk, but to help the person that receives it. It is meant to be the start of a journey to recovery, via psychoeducation, understanding oneself, and empowerment to change. Even when the person receiving the diagnosis does not feel they have a problem or does not want to change, for example the prisoner with antisocial traits, it is still used to guide their management in a way that may eventually help them, for example by repeated attempts to engage them in structured, psychologically minded interventions.

There are plenty of better ways to achieve the political ends we favour than tendentious psychiatric labelling. For example, the aggressive and persistent use of the very same levers of democracy - laws, rights and ballot boxes - that were used in the creation of the problem.

The saddest irony of attacking politicians we do not like by calling them mentally ill is that it risks turning our young people away from politics because they have mental health problems of their own. There may be an incredible 50th president of the USA out there, deciding not to join the party of her leaning because she fears that her teenage psychotic episode will be discovered. That is not the world I want to help create.

The acid test of whether public diagnosis is an idea worth defending is in its application. The movement to label and remove Donald Trump from office has been in progress since the day he entered that same office. The possibility of him being dragged from power on psychiatric grounds remains as fanciful as it was on that first day, and the collateral damage to our patients and profession, as described above, has been widespread.

Alex Langford

\section{For: rebuttal}

We are fiddling with Goldwater while the world burns. In this prestigious academic journal, we are, appropriately enough, one would think, having an academic debate about an abstract ethical principle. But if we put this problem in its true context, such an approach is dangerously absurd. We are not facing an abstract principle. We are facing a specific concrete crisis that literally threatens to engulf the world in flames.

This situation is unprecedented - sui generis, and thus endeavouring to draw on past precedents, such as an election from
1964, is wildly off the mark. The USA has gone, almost overnight, from being the cornerstone of the post Second World War global architecture, containing Russia and other potential bad actors, in alliance with Western allies such as the UK, in support of peace, stability and democratic values to a rogue pre-authoritarian state shredding our alliance to do the bidding of Vladimir Putin. In 1 year we have gone from a president who won a Nobel Peace prize to one who threatens to impulsively start a third world war, and who is afraid to visit London because he is so virulently hated there.

In my view, we have never had a US president who is so deeply and dangerously psychologically disordered and unfit. Lincoln was depressed. I have described Clinton as hypomanic. ${ }^{19}$ But not all mental illnesses are created equal. I consider that Trump's level of disturbance is of a higher order of magnitude by a factor of $10-$ the greatest psychiatric emergency of the 21st century, maybe even in history. Yet, nowhere is there a psychiatrist to be found who will even make a peep.

One of the 'Goldwater fallacies' that angers me most is the 'psychiatry has nothing to add' defence. The truth of Trump's bad behaviour, they argue, speaks for itself. So, no need for us to speak up. To quote my debate opponent 'the psychopathology of the person in question is quite clear to the public anyway, and despite our airs of expertise, a psychiatric label adds nothing meaningful to their appraisal of risk'. I invite you to come to the USA for a while and see if truth speaks for itself. Truth itself is under attack here. An unholy alliance between what I would describe as a psychopathic president, a corrupt supine Republican party and massive right wing/Russian misinformation propaganda machine has convinced a third of America that Russia did not even interfere without election, and the real criminal is Christopher Steele, the British intelligence agent who warned us we were under attack. When real news is 'fake news' and the president tweets bizarre conspiracy theories from racist websites, we are in George Orwell territory. A quote commonly attributed to Orwell goes, 'In a time of universal deceit - telling the truth is a revolutionary act'. Truth does not defend itself. And brave psychiatric revolutionaries seem to be in short supply.

On one hand, we are forbidden from diagnosing Trump 'from a distance'. But on the other, Trump will never consent to being formally examined up close. He recently had a physical and there was no evaluation by a psychiatrist, and no mental health tests employed, except a screening exam for frank dementia. If any other American had access to weapons and was threatening to use them, while showing increasing signs of what I would describe as instability, anger, paranoia, feelings of persecution and cognitive confusion, they would be involuntarily committed for psychiatric evaluation. Dr Bandy Lee, the professor of psychiatry at Yale who edited the bestselling book, The Dangerous Case of Donald Trump, has seriously proposed Trump meets standards for commitment and should be required to undergo psychiatric evaluation, whether he wants to or not. ${ }^{20} \mathrm{I}$ cannot say I disagree.

I compared enforcing the Goldwater gag order in the case of Trump to a situation where an armed gunman enters a library announcing 'everyone here is going to die today,' and when a patron shouts out, 'someone call the police,' the librarian scolds 'this is a library you must remain silent'. Only in this case, I would argue that the man is threatening to murder an entire country; the misguided librarian is the APA; and we cannot call the authorities because the homicidal patient is the authorities.

The only thing we can do is speak out. To be silent is a choice. To say psychiatry has no value to add to the discussion is a transparently cowardly excuse to justify that silence 


\section{Against: rebuttal}

No rebuttal from me would ever be as effective as simply asking people to re-read Professor Gartner's second offering, to soak up the maximum amount of absurd. Yes, he really is stating, in the British Journal of Psychiatry, that the sole survivors of the impending nuclear holocaust will be curled up in their bunkers, tinfoil hats firmly in place, wailing 'damn you, psychiatrists!' into the radioactive wind.

But alas, one of us has to stay tethered to reality. Do re-read his second offering - but with a greater goal than bemusement in mind. Re-read who he describes - a man who is corrupt, a man who does not care, a man who is dangerous. A man that he hates. A man he hates being in power.

Now ask yourself, as a psychiatrist or other healthcare professional, what it is that you do. I know what I do. I try to help people recover from suffering, to rebuild their lives, to understand themselves, to take control of their well-being. I do not decide who is fit to run my country. I do not deign to think that I, with my medical degree, should have any more of a say in that that anyone else.

I get one vote. So does everyone else. I might not like who gets elected (and believe me, as a National Health Service employee, I really do not) but that is the way it is. Professor Gartner may think Trump to be the very worst example of a human being he has ever known, and I may even agree with him, but his compatriots wanted him in power and they knew exactly what they were voting for. He should not be able to overrule them because he thinks he has a medical name for the characteristics that voters saw in Trump before marking their ballot papers.

If Professor Gartner wants to shout about his metaphorical gunman in the library, he can. The USA has robust electoral and judicial systems that I suggest he use with ferocity, like millions of his compatriots intend to.

Professor Gartner also quotes George Orwell, but has grasped the wrong end of his dystopian stick. Orwell spent the majority of his life actively rebelling against duplicitous political strategising by jumpedup subgroups against the wishes of the people. His most famous book is about a man whose political ideas got him detained and mentally altered against his will. Yet he wants to do that to Trump. That level of raging inconsistency is quite an achievement.

It was also a quote about telling the truth. The truth is that my patients are good people, who need to trust me, so that in future more people open up to me too. The truth is that I know the difference between helping someone get better and unilaterally deciding that they should not hold political office. The truth is that I would rather give up this profession entirely than associate the challenges faced by my patients with the call to remove that morally redundant husk of a man from the White House.

If you want him out (and you should), you should demonstrate that the policies and qualities that got him in are damaging and nonsensical. Vote him out. Or impeach him. Force his resignation by blockading the supply of McDonalds to the Oval Office, I do not care. But trying to remove him on grounds of mental illness will not achieve anything in the face of 63 million votes except to drive our professional reputation back to the 1960s, fan the flames of stigma, and form the butt of a few childishly worded tweets.

One final thought. Like treating mental illness, resolving a damaged political landscape is all about searching for causes and fixing them. Has Professor Gartner put even the slightest thought into why 63 million people voted for a man that dozens have described as sexist, racist, abusive, denigrating, incompetent, lazy and untruthful, who had more experience as an extra in Home Alone 2 than as a politician? Perhaps, and this is a wild assumption, those voters were sick of 'elitist' experts making all the decisions about their country, and this was the only way they had to show their anger? In this context, does Professor Gartner expect the American people to thank him gratefully for his expert medical opinion and let him quietly usher away their symbol of disgust?

Unless Professor Gartner and his supporters work with their compatriots to address the pressing concerns of voters, removing the man they detest so much on a medical technicality would only stir up their political storm even further. Are they planning to detain every president until they get one they like? Who sounds Orwellian now?

Alex Langford

For: John Gartner, PhD, 6525 N. Charles St., \#145, Baltimore, MD 21204, USA. Email: johndgartner@comcast.net; Against: Alex Langford, Whiteleaf Centre, Bierton Road, Aylesbury HP20 1EG, UK. Email: Alexander.Langford@oxfordhealth.nhs.uk; Aileen O'Brien, St. Georges University of London, Institute of Medical and Biomedical Education, London SW17 ORE, UK. Email: aobrien@sgul.ac.uk

First received 6 Jun 2018, accepted 6 Jun 2018

\section{References}

1 Sartwell C. Extreme Virtue: Truth and Leadership in Five Great American Lives. SUNY Press, 2003.

2 American Psychiatric Association. Principles of Medical Ethics with Annotations Especially Applicable to Psychiatry. APA, 1973

3 Boroson W. What psychiatrists say about Goldwater. Fact 1964; 1: 24-64.

4 Brendel R. The Goldwater rule is still relevant. Psychiatr Times 2017; 20 July (http://www.psychiatrictimes.com/couch-crisis/goldwater-rule-still-relevant).

5 Dyer A. Evolution of the so called 'Goldwater Rule:' An Ethical Analysis. Allen Dyer, 2017 (https://allendyer.files.wordpress.com/2014/12/2017-evolution-ofso-called-goldwater-rule-ver23sept17.pdf).

6 Kroll J, Pouncey C. The ethics of APA's goldwater rule. J Am Acad Psychiatry Law 2016; 44: 226-35.

7 Lee B. Our duty to warn. In The Dangerous Case of Donald Trump: 27 Psychiatrists and Mental Health Professionals Assess a President (ed B Lee). St. Martin's Press, 2017

8 Gartner J. What is Trump's psychological problem? Huffington Post 2016; 9 June.

9 McKnight W. Goldwater Rule keeps psychiatrists from commenting on Trump's mental fitness. Washington Diplomat 2017; 1 August.

10 Gerson J. How anti-Trump psychiatrists are mobilizing behind the 25th Amendment. The New Yorker 2017; 16 October.

11 Farrow M. So here's my Trump diagnosis: narcissistic personality disorder $N A T C H, O C D$, antisocial personality disorder, it includes pathological lying. Tweet (@MiaFarrow) 2017; 27 September.

12 The Sun. Bonkers Bruno locked up. The Sun 2003; 23 September

13 Parry R, Moyes S. 1200 killed by mental patients. The Sun 2013; 7 October.

14 Thomas F. Eagleton, a running mate for 18 days, dies. New York Times 2007; 5 March (http://www.nytimes.com/2007/03/05/washington/05eagleton.html).

15 BBC News. MPs Charles Walker and Kevan Jones tell of mental health issues. BBC News, 2012; 14 June (http://www.bbc.co.uk/news/uk-politics-18444516).

16 General Medical Council. Confidentiality: Good Practice in Handling Patient Information. General Medical Council, 2017 (https://www.gmc-uk.org/guidance/ethical_guidance/confidentiality.asp).

17 Van Voren R. Political abuse of psychiatry—an historical overview. Schizophr Bull 2010; 36: 33-5.

18 Metzl J. The Protest Psychosis. Beacon Press, 2010.

19 Gartner 'Donald Trump and Bill Clinton Have the Same Secret Weapon', August 25, 2015 https://newrepublic.com/article/122600/donald-trump-and-bill-clinton-have-same-secret-weapon

20 Lee B. The Dangerous Case of Donald Trump: 27 Psychiatrists and Mental Health Professionals Assess a President. St Martin's Press, 2017. 